\title{
Estradiol Synthesis and Release in Cultured Female Rat Bone Marrow Stem Cells
}

\author{
Dalei Zhang, ${ }^{1}$ Bei Yang, ${ }^{1}$ Weiying Zou, ${ }^{1}$ Xiaying Lu, ${ }^{1,2}$ Mingdi Xiong, \\ Lei Wu, ${ }^{1}$ Jinglei Wang, ${ }^{1}$ Junhong Gao, ${ }^{3}$ Sifan $\mathrm{Xu},{ }^{4}$ and Ting $\mathrm{Zou}^{1}$ \\ ${ }^{1}$ Department of Physiology, Medical College of Nanchang University, Nanchang, Jiangxi 330006, China \\ ${ }^{2}$ Department of Physiology, Gannan Medical University, Ganzhou, Jiangxi 341000, China \\ ${ }^{3}$ Institute of Acupuncture and Moxibustion, China Academy of Chinese Medical Sciences, Beijing 100700, China \\ ${ }^{4}$ Institute of Chinese Minority Traditional Medicine, Minzu University of China, Bejing 100081, China
}

Correspondence should be addressed to Ting Zou; zouttzou@yahoo.com

Received 11 September 2012; Revised 21 November 2012; Accepted 29 November 2012

Academic Editor: Thomas Skutella

Copyright (C) 2013 Dalei Zhang et al. This is an open access article distributed under the Creative Commons Attribution License, which permits unrestricted use, distribution, and reproduction in any medium, provided the original work is properly cited.

Bone marrow stem cells (BMSCs) have the capacity to differentiate into mature cell types of multiple tissues. Thus, they represent an alternative source for organ-specific cell replacement therapy in degenerative diseases. In this study, we demonstrated that female rat BMSCs could differentiate into steroidogenic cells with the capacity for de novo synthesis of Estradiol-17 $\beta$ (E2) under high glucose culture conditions with or without retinoic acid (RA). The cultured BMSCs could express the mRNA and protein for P450arom, the enzyme responsible for estrogen biosynthesis. Moreover, radioimmunoassay revealed that BMSCs cultured in the present culture system produced and secreted significant amounts of testosterone, androstenedione, and E2. In addition, RA promoted E2 secretion but did not affect the levels of androgen. These results indicate that BMSCs can synthesize and release E2 and may contribute to autologous transplantation therapy for estrogen deficiency.

\section{Introduction}

Steroid hormones play important regulatory roles in female reproduction, in which estrogen is essential for folliculogenesis beyond the antral stage and is necessary to maintain the female phenotype of ovarian somatic cells [1-4]. Estradiol-17 $\beta$ (E2), a product of androgen aromatization, is the principal estrogen and is secreted in large amounts by the large preovulatory follicles in the ovary [5]. Although the ovaries are the principal source of systemic oestrogen in the premenopausal nonpregnant woman, a number of extragonadal sites of oestrogen biosynthesis, including mesenchymal cells of the adipose tissue and skin, osteoblasts, vascular endothelial, aortic smooth-muscle cells, and brain, become the major sources of oestrogen beyond menopause. However, the total amount of oestrogen synthesized by these extragonadal sites may be small. Within these sites, E2 is probably biologically active only at local tissue level in a paracrine or intracrine fashion without significantly affecting circulating levels [6-8].

The reduction of estrogen production in the ovary may cause menopausal symptoms. In addition, premature ovarian failure may be caused by any process which reduces the number of oocytes within the ovary [9]. For example, chemotherapy can reduce ovarian reserve and affect ovarian stromal function to produce less estrogen [10]. Although estrogen replacement therapy has been established and is recommended for postmenopausal women or patients with hypogonadism, due to its beneficial effects, follicular estrogen production is regulated by a complex set of signals that synergize to produce optimal steroidogenesis [11]. Still, it is difficult to provide an optimal therapeutic dose for long-term estrogen replacement therapy. Furthermore, it is associated with a substantial risk for cardiovascular disease and breast cancer [12]. For this reason, alternative therapies such as steroidogenic cell transplantation may have advantages over 
HRT for hypogonadism. It should allow control of hormone levels in nature by hypothalamus-anterior pituitary axis.

Several earlier studies have suggested that stem cells can serve as an alternative source for various steroid hormones [13-17]. Bone marrow stem cells (BMSCs) are thought to be multipotent cells, which can replicate as undifferentiated cells and have the potential to differentiate into mature cell types of multiple tissues $[18,19]$. In the present study, we investigated whether female rat BMSCs could produce steroidogenic cells with the capacity for the synthesis of E2.

\section{Materials and Methods}

2.1. Isolation and Culture of BMSCs. Female SD rats, weighing 80 to $100 \mathrm{~g}$, were obtained from Center of Laboratory Animals of Nanchang University and used in accordance with a protocol approved by the Nanchang University Animal Care and Use Committee. The bone marrow cells were isolated from femurs and tibias of female rats by flushing the shaft with phosphate-buffered saline (PBS) using needles, and the cells were further dispersed several times by gentle, repeated pipetting with a sterile pipet. The dissociated cells were seeded in $75 \mathrm{~cm}^{2}$ culture flasks for the primary culture in the high glucose $(4.5 \mathrm{~g} / \mathrm{L})$ Dulbecco's modified Eagle's medium (DMEM, Hyclone, Utah) supplemented with 10\% fetal bovine serum (FBS, Stem Cell Tech Inc., Canada) and incubated at $37^{\circ} \mathrm{C}$ in a water-saturated atmosphere of $95 \%$ air and $5 \% \mathrm{CO}_{2}$. The nonadherent cells were removed by washing with PBS and replacing the fresh complete medium every 3 or 4 days. The adherent cells were passaged every 7 days by harvesting the cells with $0.25 \%$ trypsin/0.02\% EDTA, and replating at a $1: 4$ dilution.

2.2. Induction of BMSC Differentiation In Vitro. Cultured cells at passage 3 were recovered and used in these experiments. BMSCs were reincubated in 12-well culture plates (Nunc, Denmark) at a density of $2 \times 10^{5} /$ well in the high glucose $(4.5 \mathrm{~g} / \mathrm{L})$ DMEM containing $10 \%$ FBS supplemented with or without $10^{-5} \mathrm{~mol} / \mathrm{L}$ all-trans retinoic acid (RA, Sigma) for 4 days. Differentiated cells from the BMSCs were analyzed by immunocytochemical staining or RTPCR analysis for expression of aromatase cytochrome P450 (P450arom). The levels of testosterone (T), androstenedione (ASD), and E2 in culture media were measured by radioimmunoassay (RIA).

2.3. Immunocytochemistry of P450arom. BMSCs were fixed in $4 \%$ acetone at $4^{\circ} \mathrm{C}$ for 15 minutes and washed 3 times with PBS. Endogenous peroxidase was quenched by incubating the fixed cells with $3 \% \mathrm{H}_{2} \mathrm{O}_{2}$ in methanol for 20 minutes. After being washed with PBS for $15 \mathrm{~min}$ ( $5 \mathrm{~min} \times 3$ times), cells were incubated for 20 minutes with $10 \%$ normal goat serum; then with a rabbit polyclonal antibody to aromatase (Boster Co., Wuhan, China), they were diluted 1:100 in PBS overnight at $4^{\circ} \mathrm{C}$. The negative control was prepared in an identical manner except that the primary antibody was replaced with normal serum. After washing with PBS, cells were incubated with horseradish peroxidase-conjugated goat anti-rabbit IgG for 1 hour at room temperature. After washing, the immunoreaction was detected by using DAB system.

2.4. Real-Time PCR Analysis. Total RNA was extracted from cultured BMSCs using Trizol reagent (Sigma, St. Louis, MO) and was reverse transcribed into cDNA using the First-Strand cDNA synthesis kit. Real-time PCR was performed to quantify the samples' cDNA copies using SYBR premix ExTaqTM fluorescent quantitation PCR kit (TaKaRa, Japan). The CYP19 primers forward: 5 '-GCTTCTCATCGCAGSGTAT-3', reverse: 5 -CAAGGGTAAATTCATTGGG-3'. The $\beta$-actin primers forward: 5 '-GGAAATCGTGCGTGACATTAAA3', reverse: 5'-TGCGGCAGTGGCCATC-3'. Conditions for PCR were 40 cycles of $95^{\circ} \mathrm{C}$ for 5 seconds and $60^{\circ} \mathrm{C}$ for 34 seconds. The cycle threshold $(\mathrm{Ct})$ was set up at the level that reflected the best kinetic PCR parameters, and melting curves were acquired and analyzed. The $2^{-\Delta \Delta \mathrm{Ct}}$ method of relative quantification was used to estimate the copy numbers in CYP19 gene.

2.5. T, ASD and E2 Measurement. Before culture (defined as time 0 ) and 1,2,3, or 4 days after culture, cell culture medium was centrifuged and collected, and the levels of T, ASD and E2 were measured by Beijing Sino-UK Institute of Biological Technology.

2.6. Statistical Analysis. The experiment was repeated a minimum of three times. All data were expressed as the mean \pm SD and analyzed by ANOVA and Ducan's multiple range test using the SAS 8.0 software. $P<0.05$ was considered significantly different.

\section{Results}

3.1. RT-PCR Analysis for CYP19 mRNA Expression. RT-PCR analysis showed that there was expression of aromatase gene CYP19 in BMSCs cultured for 4 days in a high glucose DMEM, and the expression was significantly higher than that in 0 day cells. Furthermore, we investigated the effects of RA on BMSC differentiation in vitro. The result showed that the expression of CYP19 mRNA was not further elevated by RA treatment at a concentration of $10^{-5} \mathrm{~mol} / \mathrm{L}$ (Figure 1).

3.2. Immunocytochemical Analysis of P450arom. To elucidate the capacity of BMSCs to generate E2, we examined the expression of P450arom protein, the enzyme responsible for estrogen biosynthesis, by immunocytochemical staining. The results showed that P450arom was expressed in BMSCs cultured in a high glucose culture condition alone or in combination with RA treatment, with a positive labeling in part of the cells, and it was primarily immunolocalized in the cytoplasm (Figure 2).

3.3. RIA for E2. To evaluate E2 biosynthesis and release in cultured BMSCs, the levels of E2 in culture medium were 


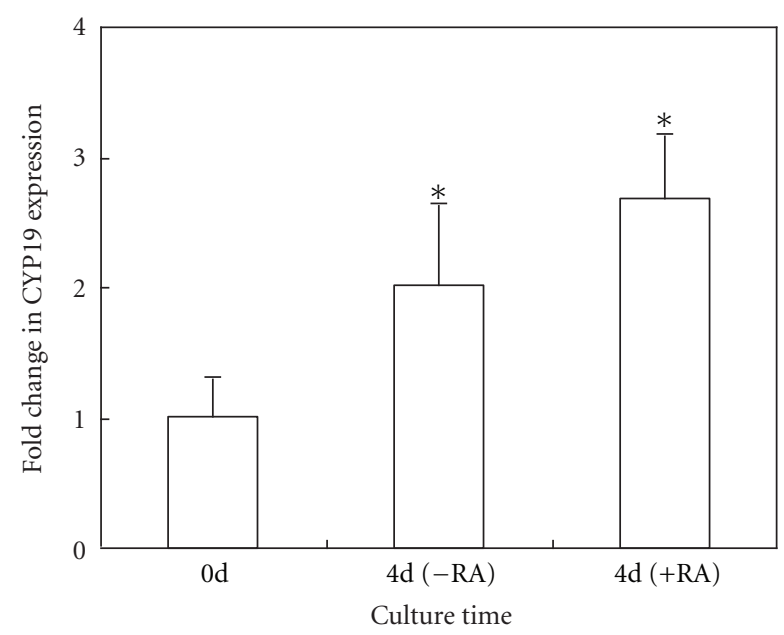

FIgURE 1: Real-time PCR analysis of CYP19 expression in rat BMSCs. The expression of CYP19 was determined relative to the $\beta$-actin expression. Expression data $(n=5)$ were reported as fold change $\left(2^{-\Delta \Delta \mathrm{Ct}}\right)$. BMSCs cultured in high glucose DMEM alone (control) or in combination with RA treatment $\left(10^{-5} \mathrm{~mol} / \mathrm{L}\right)$ for 4 days as compared with 0 day cells. The experiment was repeated three times. Statistical significance was determined by a $t$-test. ${ }^{*} P<$ 0.05 , versus 0 day.

measured by RIA. Before incubation, the culture medium of BMSCs at passage 3 contained a low concentration of E2. After exposure to a high glucose condition for 1 day, E2 levels were increased significantly. However, E2 content was not obviously altered after prolonged culture time (2-4 days). Similar results were observed in cultured BMSCs that were given a combined treatment with high glucose and RA. The maximal effect of RA was observed in BMSCs cultured for 48 hours, and the release of E2 significantly increased compared with the high glucose medium alone (Figure 3 ).

3.4. RIA for $T$ and ASD. To investigate de novo synthesis of $\mathrm{E} 2$, we measured the levels of T and ASD in medium by RIA. After BMSC culture for 4 days and 1 day in high glucose medium alone or together with RA, the release of T and ASD significantly increased, respectively. However, there were no obvious differences in the levels of T and ASD between the high glucose group and combination group (Figures 4 and $5)$. In addition, prolonged culture time (2-4d) had no effect on the release of ASD (Figure 5).

\section{Discussion}

The high degree of stem cell plasticity provides a promising strategy for cell replacement therapy. During the past several years, a great deal of attention has been focused on the plasticity of BMSCs. Since BMSCs have tremendous differentiative potential, they can differentiate in vitro and in vivo into mature cells of the heart, liver, kidney, lungs, GI tract, skin, bone, muscle, cartilage, fat, endothelium, and brain. These BMSC-derived cells have been shown to contribute to clinical treatment of genetic disease or tissue repair [20-29]. In the present study, we investigated the ability of the BMSCs to generate steroidogenic cells and release E2 in vitro. Our study revealed that BMSCs cultured in high glucose DMEM with or without RA were capable of differentiating into cells that produced and secreted significant amounts of E2.

Under physiological conditions, E2 is produced de novo from cholesterol and synthesized by the ovary in a sequential manner. Steroidogenic granulosa and theca cells cooperate under gonadotropin control to produce estrogens by stimulating synthesis of steroidogenic enzyme messenger RNAs [11]. In the theca, under the influence of LH, cholesterol is converted to pregnenolone and metabolized through a series of substrates ending in androgen production. Theca cell-derived androgens transported to the granulosa cells of developing follicles, where they are aromatized to oestrogens by P450arom, the product of the CYP19 gene, which is responsible for conversion of $\mathrm{C} 19$ steroids to estrogen [2, 6, 30]. In our culture systems, P450arom mRNA and protein were expressed in BMSCs, which also produced and released $\mathrm{T}$ and ASD. These results suggested that BMSCs could produce steroidogenic cells with the capacity for the synthesis of E2.

In recent years, some studies found that transfection of BMSCs from human and murine with steroidogenic factor 1 (SF-1, an essential factor for differentiation of the pituitarygonadal axis) can transform BMSCs into steroidogenic cells, which produce various steroid hormones, including E2, and expressed mRNA for P450arom [16, 17]. When transplanted into immature rat testes, adherent marrow-derived cells were found to be engrafted and differentiated into steroidogenic cells that were indistinguishable from Leydig cells [17]. These results provided evidence that BMSCs were capable of differentiating into steroidogenic cells and represented a useful source of stem cells for cell transplantation therapy. In this study, without forced expression of SF-1, we demonstrated the ability of the BMSCs to spontaneously form steroidogenic cells and secrete E2 under a high glucose condition.

$\mathrm{RA}$ is well known as the biologically active form of vitamin $\mathrm{A}$ and has been shown to play an important role in normal embryonic development and maintenance of differentiation in the adult organism [31]. Previous studies showed that RA could induce BMSCs to differentiate into male germ cells [32] and stimulate E2 and T synthesis in rat hippocampal slice cultures [33]. Therefore, we examined the effects of RA on E2 and T biosynthesis in cultured female rat BMSCs. In the present study, BMSCs were incubated in the absence or presence of RA to investigate RA-induced differentiation of BMSCs to steroidogenic cells in vitro. Compared with high glucose medium alone, E2 secretion was stimulated by RA treatment without any increase in the levels of androgen, suggesting that RA, at least at a concentration of $10^{-5} \mathrm{~mol} / \mathrm{L}$, may promote the differentiation of BMSCs to estrogen-producing cells.

A great deal of efforts had been directed at understanding what role stem cells may play in the physiology and pathology of the mammalian female gonads [34]. Over the past few years, some studies found that bone marrow transplantation (BMT) generated immature oocytes and rescued long-term 


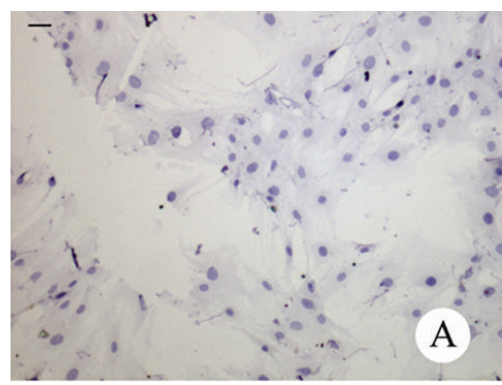

(a)

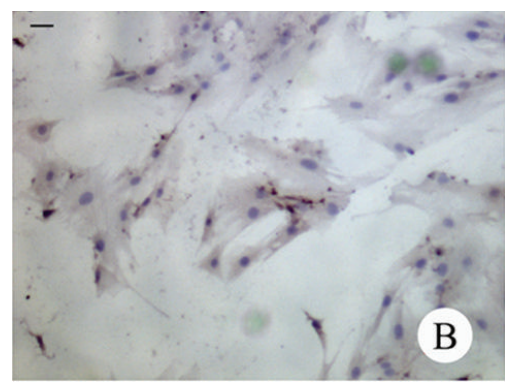

(b)

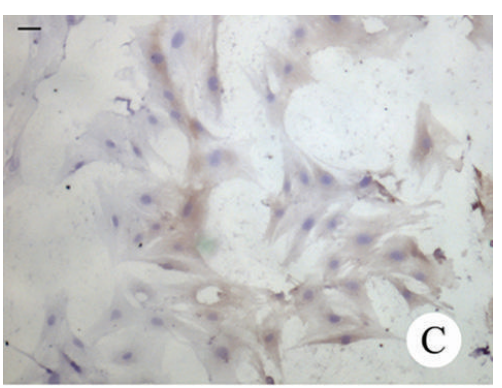

(c)

FIGURE 2: Immunocytochemical staining of P450arom in rat BMSCs cultured for 4 days. (a), negative staining; (b), control group; (c), RA treatment group. P450arom was expressed in BMSCs cultured in a high glucose culture condition alone (control group) or in combination with RA treatment. Scale bar: $20 \mu \mathrm{m}$.

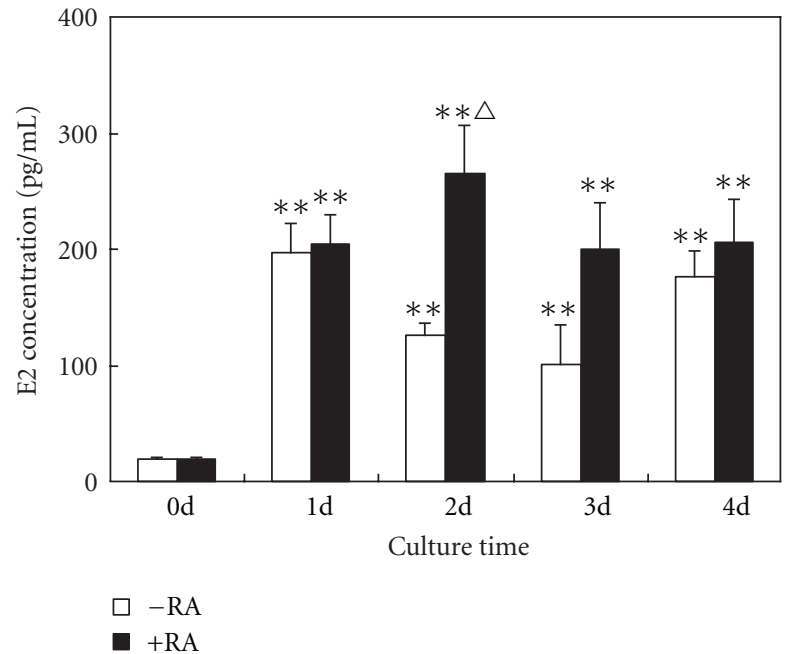

FIgURE 3: Measurement of E2 concentrations in culture media by RIA. Compared with 0 day cells, the release of E2 significantly increased in rat BMSCs cultured in a high glucose DMEM or in combination with RA for 1-4 days. The experiment was repeated three times. Values represent means $\pm \operatorname{SD}(n=5) .{ }^{* *} P<0.01$, versus 0 day; ${ }^{\triangle} P<0.01$, versus high glucose DMEM.

fertility in a preclinical mouse model of chemotherapyinduced premature ovarian failure. Although all offspring were derived from the recipient germline, donor-derived oocytes were generated in ovaries of recipients after BMT [35]. Furthermore, MSC transplantation can improve ovarian function and structure damaged by chemotherapy, and the paracrine mediators secreted by MSC might be involved in the repair of damaged ovaries [36]. These results suggested that the potential of BMSCs for ameliorating female reproductive function was involved in reversal of both ovarian germline and somatic cell insufficiency.

In a previous report, mouse embryonic stem cells in culture developed into oogonia that could enter meiosis, recruit adjacent cells to form follicle-like structures, which expressed aromatase and secreted E2 [15]. In addition, mouse-induced pluripotent stem cells cocultured with ovarian granulosa cells in vitro could form granulosa cell-like cells and secret E2

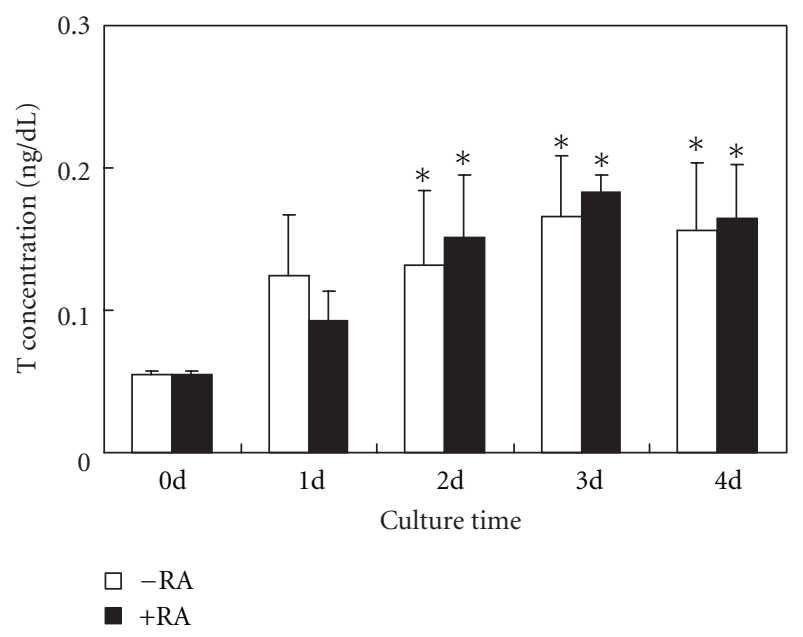

FIgURE 4: Measurement of T concentrations in culture media by RIA. Compared with 0 day cells, the release of $\mathrm{T}$ significantly increased in rat BMSCs cultured in a high glucose DMEM for 2-4 days. RA treatment did not obviously increase the levels of ASD. The experiment was repeated three times. Values represent means \pm SD $(n=5) .{ }^{*} P<0.05$, versus 0 day; ${ }^{* *} P<0.01$, versus 0 day.

[37]. BMSCs in our culture systems did not form folliclelike structures, nor did exhibit the morphology of mature ovarian cells. However, they expressed P450arom, suggesting that BMSCs have the ability to synthesize and to release E2, which may contribute to autologous transplantation therapy of BMSCs for hypogonadism.

\section{Conclusion}

In this study, we showed that female rat BMSCs cultured in high glucose DMEM with or without RA could express CYP19 and P450arom, and excrete T, ASD, and E2. These results indicated that the cultured BMSCs could produce steroidogenic cells with the capacity for E2 synthesis. This study would help to provide basis for clinical application of BMSCs in autologous cell transplantation therapy for patients with estrogen deficiency. 


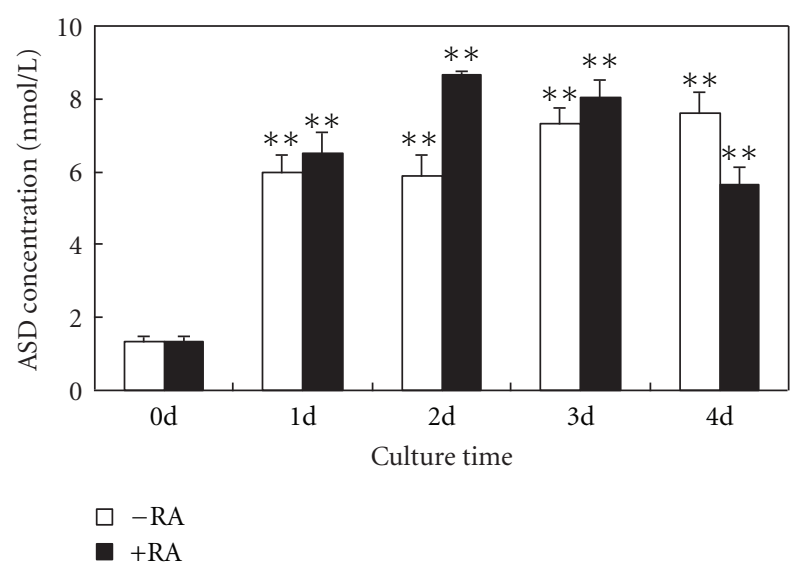

FIGURE 5: Measurement of ASD concentrations in culture media by RIA. Compared with 0 day cells, the release of ASD significantly increased in rat BMSCs cultured in a high glucose DMEM for 1-4 days. RA treatment did not obviously increase the levels of ASD. The experiment was repeated three times. Values represent means \pm SD $(n=5) .{ }^{*} P<0.05$, versus 0 day; ${ }^{* *} P<0.01$, versus 0 day.

\section{Conflict of Interests}

The authors declare that they have no conflict of interests.

\section{Authors' Contribution}

D. Zhang, B. Yang, and W. Zou equally contributed to this work.

\section{Acknowledgment}

This work was supported by the National Natural Science Foundation of China (no. 30960409 and 81060056).

\section{References}

[1] E. Y. Adashi and A. J. W. Hsueh, "Estrogens augment the stimulation of ovarian aromatase activity by follicle-stimulating hormone in cultured rat granulosa cells," Journal of Biological Chemistry, vol. 257, no. 11, pp. 6077-6083, 1982.

[2] A. E. Drummond, "The role of steroids in follicular growth," Reproductive Biology and Endocrinology, vol. 4, article 16, 2006.

[3] F. Otsuka, R. K. Moore, X. Wang, S. Sharma, T. Miyoshi, and S. Shimasaki, "Essential role of the oocyte in estrogen amplification of follicle-stimulating hormone signaling in granulosa cells," Endocrinology, vol. 146, no. 8, pp. 3362-3367, 2005.

[4] L. Z. Zhuang, E. Y. Adashi, and A. J. Hsuch, "Direct enhancement of gonadotropin-stimulated ovarian estrogen biosynthesis by estrogen and clomiphene citrate.," Endocrinology, vol. 110, no. 6, pp. 2219-2221, 1982.

[5] C. P. Channing and S. P. Coudert, "Contribution of granulosa cells and follicular fluid to ovarian estrogen secretion in the rhesus monkey in vivo," Endocrinology, vol. 98, no. 3, pp. 590-597, 1976.

[6] E. R. Simpson, Y. Zhao, V. R. Agarwal et al., "Aromatase expression in health and disease," Recent Progress in Hormone Research, vol. 52, pp. 185-214, 1997.
[7] E. R. Simpson and S. R. Davis, "Minireview: aromatase and the regulation of estrogen biosynthesis-some new perspectives," Endocrinology, vol. 142, no. 11, pp. 4589-4594, 2001.

[8] E. R. Simpson, "Role of aromatase in sex steroid action," Journal of Molecular Endocrinology, vol. 25, no. 2, pp. 149-156, 2000.

[9] G. S. Conway, "Premature ovarian failure," British Medical Bulletin, vol. 56, no. 3, pp. 643-649, 2000.

[10] O. Oktem and K. Oktay, "Quantitative assessment of the impact of chemotherapy on ovarian follicle reserve and stromal function," Cancer, vol. 110, no. 10, pp. 2222-2229, 2007.

[11] Z. Shoham and M. Schachter, "Estrogen biosynthesis-regulation, action, remote effects, and value of monitoring in ovarian stimulation cycles," Fertility and Sterility, vol. 65, no. 4, pp. 687-701, 1996.

[12] H. P. Women, "Risks and benefits of estrogen plus progestin in healthy postmenopausal women: principal results from the women's health initiative randomized controlled trial," The Journal of the American Medical Association, vol. 288, pp. 321-333, 2002.

[13] P. A. Crawford, Y. Sadovsky, and J. Milbrandt, "Nuclear receptor steroidogenic factor 1 directs embryonic stem cells toward the steroidogenic lineage," Molecular and Cellular Biology, vol. 17, no. 7, pp. 3997-4006, 1997.

[14] S. Gondo, T. Yanase, T. Okabe et al., "SF-1/Ad4BP transforms primary long-term cultured bone marrow cells into ACTHresponsive steroidogenic cells," Genes to Cells, vol. 9, no. 12, pp. 1239-1247, 2004.

[15] K. Hübner, G. Fuhrmann, L. K. Christenson et al., "Derivation of oocytes from mouse embryonic stem cells," Science, vol. 300, no. 5623, pp. 1251-1256, 2003.

[16] T. Tanaka, S. Gondo, T. Okabe et al., "Steroidogenic factor 1/adrenal 4 binding protein transforms human bone marrow mesenchymal cells into steroidogenic cells," Journal of Molecular Endocrinology, vol. 39, no. 5-6, pp. 343-350, 2007.

[17] T. Yazawa, T. Mizutani, K. Yamada et al., "Differentiation of adult stem cells derived from bone marrow stroma into Leydig or adrenocortical cells," Endocrinology, vol. 147, no. 9, pp. 4104-4111, 2006.

[18] J. E. Grove, E. Bruscia, and D. S. Krause, "Plasticity of bone marrow-derived stem cells," Stem Cells, vol. 22, no. 4, pp. 487-500, 2004.

[19] D. S. Krause, "Plasticity of marrow-derived stem cells," Gene Therapy, vol. 9, no. 11, pp. 754-758, 2002.

[20] M. A. Eglitis and É. Mezey, "Hematopoietic cells differentiate into both microglia and macroglia in the brains of adult mice," Proceedings of the National Academy of Sciences of the United States of America, vol. 94, no. 8, pp. 4080-4085, 1997.

[21] G. Ferrari, G. Cusella-De Angelis, M. Coletta et al., "Muscle regeneration by bone marrow-derived myogenic progenitors," Science, vol. 279, no. 5356, pp. 1528-1530, 1998.

[22] D. C. Hess, W. D. Hill, A. Martin-Studdard, J. Carroll, J. Brailer, and J. Carothers, "Bone marrow as a source of endothelial cells and NeuN-expressing cells after stroke," Stroke, vol. 33, no. 5, pp. 1362-1368, 2002.

[23] S. Kale, A. Karihaloo, P. R. Clark, M. Kashgarian, D. S. Krause, and L. G. Cantley, "Bone marrow stem cells contribute to repair of the ischemically injured renal tubule," Journal of Clinical Investigation, vol. 112, no. 1, pp. 42-49, 2003.

[24] D. S. Krause, N. D. Theise, M. I. Collector et al., "Multi-organ, multi-lineage engraftment by a single bone marrow-derived stem cell," Cell, vol. 105, no. 3, pp. 369-377, 2001. 
[25] É. Mezey, S. Key, G. Vogelsang, I. Szalayova, G. David Lange, and B. Crain, "Transplanted bone marrow generates new neurons in human brains," Proceedings of the National Academy of Sciences of the United States of America, vol. 100, no. 3, pp. 1364-1369, 2003.

[26] D. Orlic, J. Kajstura, S. Chimenti et al., "Bone marrow cells regenerate infarcted myocardium," Nature, vol. 410, no. 6829, pp. 701-705, 2001.

[27] B. E. Petersen, W. C. Bowen, K. D. Patrene et al., "Bone marrow as a potential source of hepatic oval cells," Science, vol. 284, no. 5417, pp. 1168-1170, 1999.

[28] M. F. Pittenger, A. M. Mackay, S. C. Beck et al., "Multilineage potential of adult human mesenchymal stem cells," Science, vol. 284, no. 5411, pp. 143-147, 1999.

[29] N. D. Theise, M. Nimmakayalu, R. Gardner et al., "Liver from bone marrow in humans," Hepatology, vol. 32, no. 1, pp. 11-16, 2000.

[30] E. R. Simpson, M. S. Mahendroo, G. D. Means et al., "Aromatase cytochrome P450, the enzyme responsible for estrogen biosynthesis," Endocrine Reviews, vol. 15, no. 3, pp. 342-355, 1994.

[31] S. A. Ross, P. J. McCaffery, U. C. Drager, and L. M. De Luca, "Retinoids in embryonal development," Physiological Reviews, vol. 80, no. 3, pp. 1021-1054, 2000.

[32] J. Hua, S. Pan, C. Yang, W. Dong, Z. Dou, and K. S. Sidhu, "Derivation of male germ cell-like lineage from human fetal bone marrow stem cells," Reproductive BioMedicine Online, vol. 19, no. 1, pp. 99-105, 2009.

[33] E. Munetsuna, Y. Hojo, M. Hattori et al., "Retinoic acid stimulates $17 \beta$-estradiol and testosterone synthesis in rat hippocampal slice cultures," Endocrinology, vol. 150, no. 9, pp. 4260-4269, 2009.

[34] J. L. Tilly and B. R. Rueda, "Minireview: stem cell contribution to ovarian development, function, and disease," Endocrinology, vol. 149, no. 9, pp. 4307-4311, 2008.

[35] H. J. Lee, K. Selesniemi, Y. Niikura et al., "Bone marrow transplantation generates immature oocytes and rescues long-term fertility in a preclinical mouse model of chemotherapy-induced premature ovarian failure," Journal of Clinical Oncology, vol. 25, no. 22, pp. 3198-3204, 2007.

[36] X. Fu, Y. He, C. Xie, and W. Liu, "Bone marrow mesenchymal stem cell transplantation improves ovarian function and structure in rats with chemotherapy-induced ovarian damage," Cytotherapy, vol. 10, no. 4, pp. 353-363, 2008.

[37] Y. Kang, M. J. Cheng, and C. J. Xu, "Secretion of oestrogen from murine-induced pluripotent stem cells co-cultured with ovarian granulosa cells in vitro," Cell Biology International, vol. 35, no. 9, pp. 871-874, 2011. 

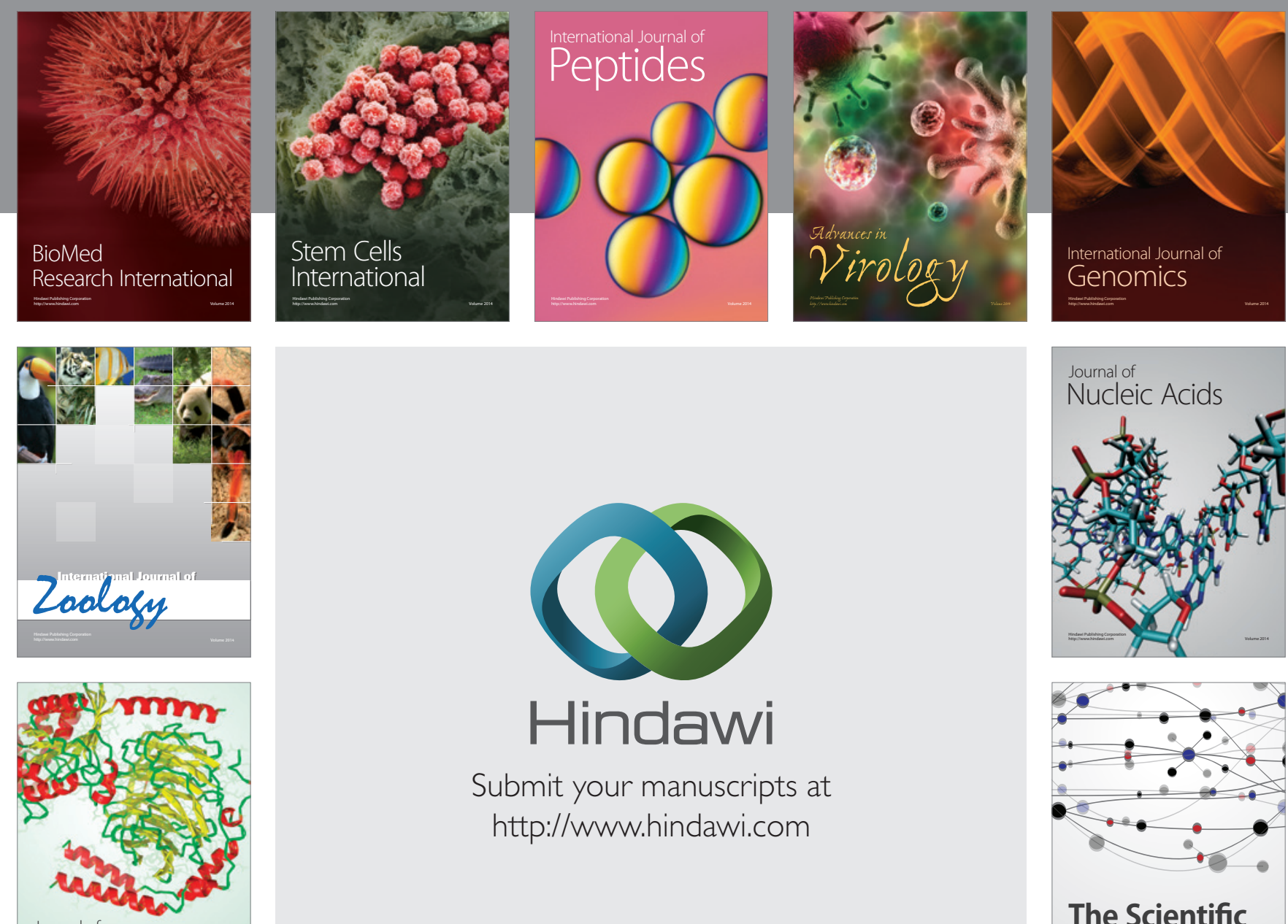

Submit your manuscripts at

http://www.hindawi.com

Journal of
Signal Transduction
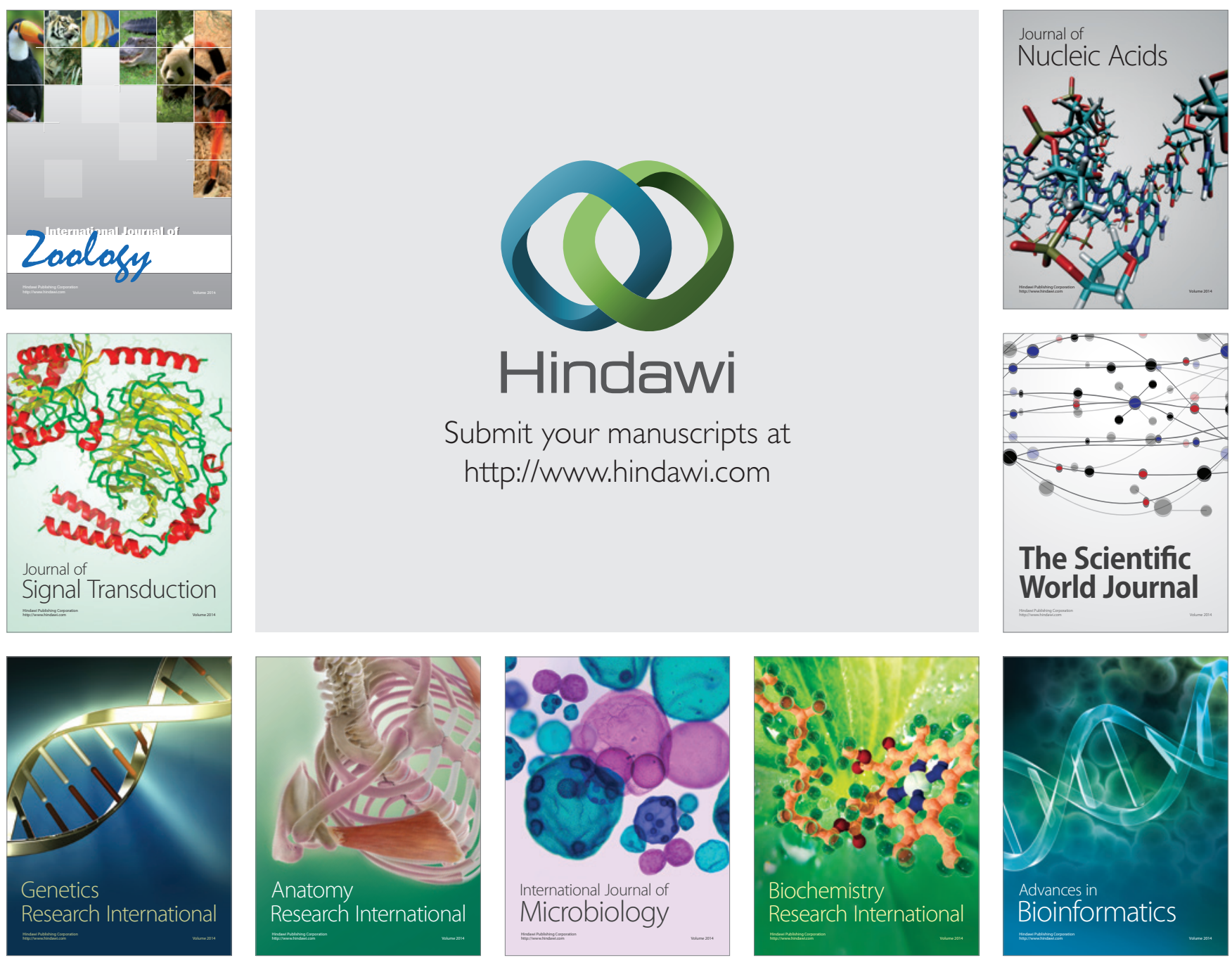

The Scientific World Journal
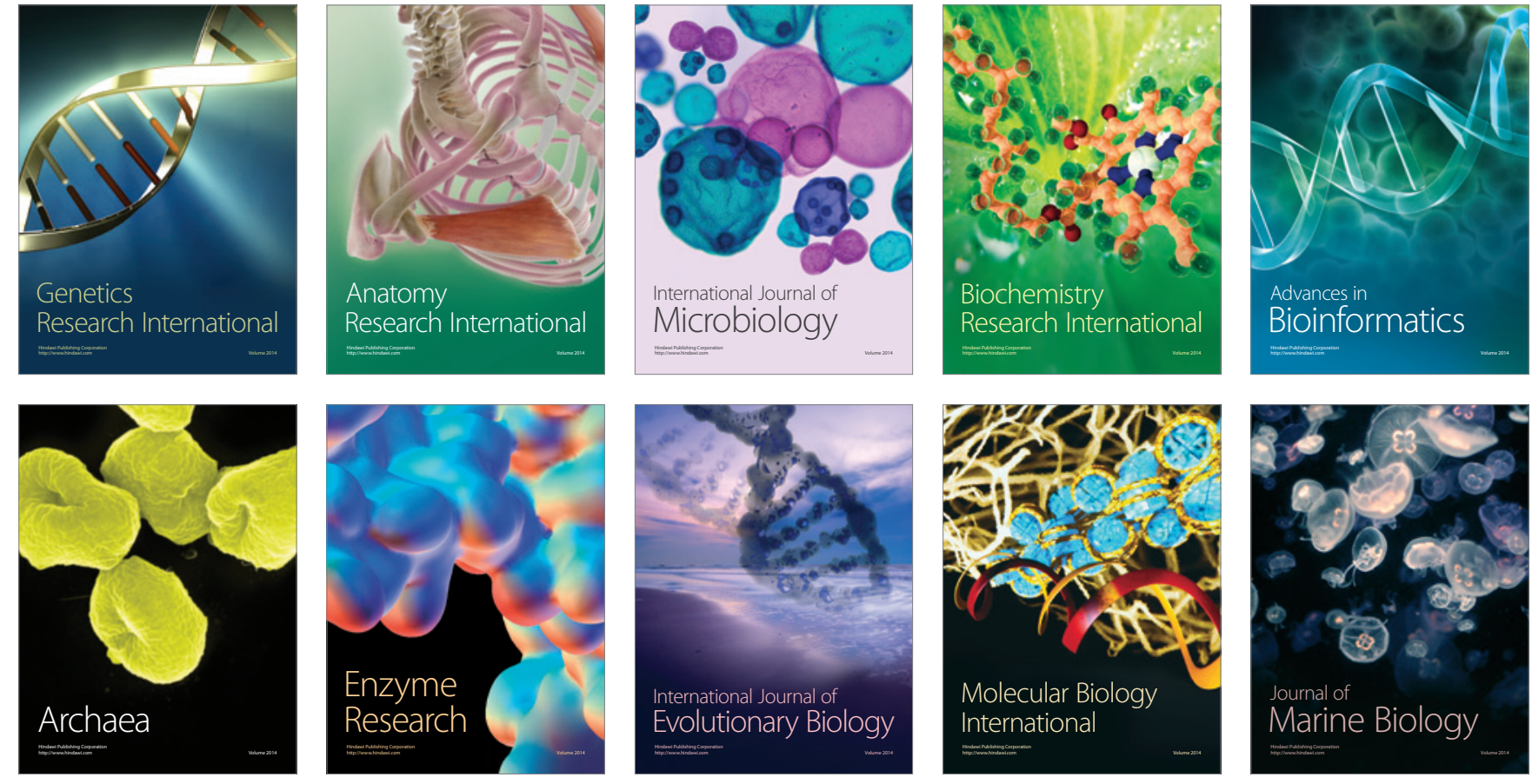